\title{
ECMO: an evolving chapter
}

\author{
Suneel Kumar Pooboni ${ }^{1}$ (D)
}

Received: 3 March 2021 / Revised: 12 March 2021 / Accepted: 18 March 2021 / Published online: 5 April 2021

(C) Indian Association of Cardiovascular-Thoracic Surgeons 2021

Extra corporeal membrane oxygenation (ECMO) is a great addition to the armamentarium for supporting life and saving critically ill patients when they cannot be saved by maximal conventional management. Our tributes are to the great pioneers who thought of the possibilities and made this happen. It took a few decades to devise, modify and perfect the process, which is still undergoing further developments. It happened due to the intelligence, dedication, and perseverance of great professionals in the medical field. Our pioneers had dreams to develop machines for providing mechanical circulatory support and faced plenty of hardships in chasing them. Their successes and failures are quite fascinating in appreciating the history of ECMO. It is still one of the youngest sciences known to mankind. India has seen phenomenal improvement in the practice of ECMO in the last decade. We begin this journey by publishing this special issue on ECMO, by making an effort to bring global experts together to guide us on the relevant topics of their expertise.

The principles of extra corporeal life support (ECLS) are similar to the techniques followed by cardiac surgeons, as the roots are the same. In India, though ECMO was occasionally used for extending cardiopulmonary units in cardiac intensive care unit (CICU), its usage for predominantly respiratory indications started in the last decade. Today we are seeing many institutions taking the help of ECMO in saving salvageable terminally ill respiratory and multi-system complications [1]. Thanks to the efforts of many similar minded physicians interested in practicing ECMO, the practice has become much more widely available, but there is still a need for further improvement. The swine flu pandemic was an occasion to test the usefulness of ECMO. Today, it's the testing time for its efficiency in saving lives in the corona virus disease 2019 (COVID-19) pandemic. In a pandemic, priority goes for

Suneel Kumar Pooboni poobonisk@gmail.com

1 Department of Pediatric Critical Care, Mediclinic Airport Road Hospital, Abu Dhabi, UAE providing affordable health care in primary and secondary care, prior to tertiary care.

ECMO is still seen as a costly procedure, not within the reach of the common man. Ethically, we cannot deny the chances of life to any deserving person. I was pleasantly surprised to see organizations permitting insured people to undergo treatment in ECMO-approved institutions. Sometimes, representing the chances of survival of a critically ill patient to the medical board might help in getting the approval for treatment. We are hopeful of a day, not in the distant future, when the technique of ECMO will be brought within the affordability for a middle-income group person. What changes can we make to bridge this gap? I hope, by making further advancements in the design of cannulas and membrane oxygenators and encouraging local manufacturing within India [2], it would be possible to bring down the cost factor.

ECLS is an ever-expanding science. It involves contributions from experienced physicians from different disciplines of Medicine. We made a genuine effort in having the input from eminent physicians in the field to get the best possible advice on the subject.

Similar to the growth of many advanced technologies, the availability of ECMO services is limited to few tertiary centers and only a few states within the country. I see the need for regulation of the practice of ECMO and spreading its knowledge and practice to all states. As the services are not available in all states, how can we make the facilities available to deserving patients? The majority of critical care transport teams are used to transfer reasonably stable patients from one institution to the other. It is essential to initiate ECMO prior to transfer of the patient when they meet the criteria for going on to ECLS, rather than transferring them on maximal ventilatory support. ECMO deserving patients are the most unstable as the only factor which helps in their stabilization is putting them on ECMO. The mortality and morbidity for these patients can improve if we adopt technology for cannulating them at referring centers and bring them to ECMO centers whilst on ECMO by utilizing Mobile ECMO technology [3]. For short distances (up to 200-300 km), road transfer is satisfactory. For longer distances, helicopter transfers are 
necessary. Train transport for critical care is an innovative method which utilizes our many inter-connecting superfast trains (https://www.indiatimes.com/news/india/india-s-firstac-ambulance-on-rails-will-rush-to-action-during-disasters273133.html). It needs further planning and expert execution.

I hope the brilliant young minds with guidance from experienced seniors should be able to work together to bring further innovations to our practice of extra corporeal life support. There are troubled times ahead with the arrival of fulminant new viruses and their mutations, multi-drug-resistant bacterial infections and fungal infections testing the way we practice Medicine. Injuries dealt to the body can be similar as those by pathogens or by the body's own immunological response to the pathogen; ECMO remains the best support mechanism for both cases due to their shared common pathway.

As medicine is a continuous process to learn and re-learn by sharing our experiences with colleagues globally, we continue to engage in this process through SWAAC ELSO (South Asia, West Asia Africa chapter of Extra Corporeal Life Support Organization) [4]. I hope the articles in this special edition on ECMO would be helpful to strengthen your foundations in understanding and practicing ECMO. It is my immense pleasure to work together with Dr. OP Yadava and Dr. Sunder in this long journey whilst executing my editorial responsibilities! I am grateful to all my colleagues who contributed to this edition by sparing their valuable time. I am fortunate to bring the blessings from Prof Robert Bartlett, who has been kind enough to guide my journey through this critical field of ECMO with his love and kindness.

I hope our enthusiastic readers find this supplement useful. Happy reading!

\section{Declarations}

Conflict of interest The author declares no competing interests.

Research involving human participants and/or animals I am not reporting new research involving human participants and/ or animals.

Informed consent I give my consent for publication.

\section{References}

1. Bartlett RH. ECMO: the next ten years. Egypt J Crit Care Med. 2016;4:7-10.

2. The Economics of ECMO., Extracorporeal Life Support: The ELSO Red Book. 5th Edition ISBN 978-0-9656756-5-9

3. Pooboni S. ECMO: an Indian perspective, challenges and opportunities. J Pediatr Crit Care. 2017;4:33-37.

4. Pooboni S. SWAC ELSO: past, present and future. Qatar Med J. 2017. https://doi.org/10.5339/qmj.2017.swacelso.9.

Publisher's note Springer Nature remains neutral with regard to jurisdictional claims in published maps and institutional affiliations. 